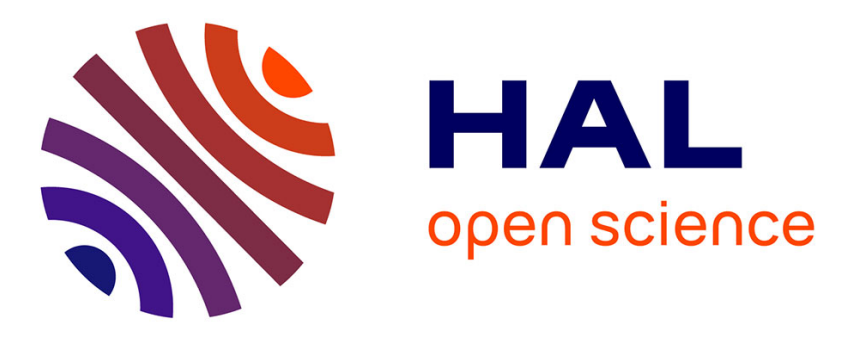

\title{
Analysis of the occurrence and distribution of the Omp25/Omp31 family of surface proteins in the six classical Brucella species
}

Ana I. Martín-Martín, Paola Caro-Hernández, Pilar Sancho, Carmen Tejedor, Axel Cloeckaert, Luis Fernández-Lago, Nieves Vizcaíno

\section{To cite this version:}

Ana I. Martín-Martín, Paola Caro-Hernández, Pilar Sancho, Carmen Tejedor, Axel Cloeckaert, et al.. Analysis of the occurrence and distribution of the Omp25/Omp31 family of surface proteins in the six classical Brucella species. Veterinary Microbiology, 2009, 137 (1-2), pp.74. 10.1016/j.vetmic.2008.12.003 . hal-00532539

\section{HAL Id: hal-00532539 \\ https://hal.science/hal-00532539}

Submitted on 4 Nov 2010

HAL is a multi-disciplinary open access archive for the deposit and dissemination of scientific research documents, whether they are published or not. The documents may come from teaching and research institutions in France or abroad, or from public or private research centers.
L'archive ouverte pluridisciplinaire HAL, est destinée au dépôt et à la diffusion de documents scientifiques de niveau recherche, publiés ou non, émanant des établissements d'enseignement et de recherche français ou étrangers, des laboratoires publics ou privés. 


\section{Accepted Manuscript}

Title: Analysis of the occurrence and distribution of the Omp25/Omp31 family of surface proteins in the six classical Brucella species

Authors: Ana I. Martín-Martín, Paola Caro-Hernández, Pilar Sancho, Carmen Tejedor, Axel Cloeckaert, Luis

Fernández-Lago, Nieves Vizcaíno

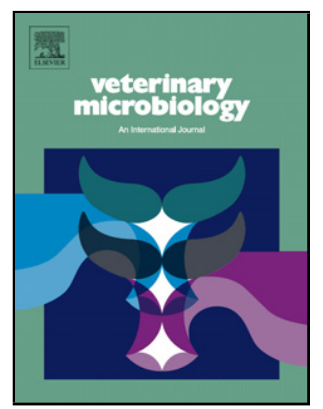

PII:

DOI:

S0378-1135(08)00564-6

Reference: doi:10.1016/j.vetmic.2008.12.003

VETMIC 4292

To appear in: $\quad$ VETMIC

Received date: $\quad 16-9-2008$

Revised date: $\quad 1-12-2008$

Accepted date: $\quad$ 2-12-2008

Please cite this article as: Martín-Martín, A.I., Caro-Hernández, P., Sancho, P., Tejedor, C., Cloeckaert, A., Fernández-Lago, L., Vizcaíno, N., Analysis of the occurrence and distribution of the Omp25/Omp31 family of surface proteins in the six classical Brucella species, Veterinary Microbiology (2008), doi:10.1016/j.vetmic.2008.12.003

This is a PDF file of an unedited manuscript that has been accepted for publication. As a service to our customers we are providing this early version of the manuscript. The manuscript will undergo copyediting, typesetting, and review of the resulting proof before it is published in its final form. Please note that during the production process errors may be discovered which could affect the content, and all legal disclaimers that apply to the journal pertain. 
3

4

6

7

8

9

10

11

12

13

14

15

16

17

18

19

20

21

22

E-mail address: vizcaino@usal.es

3

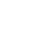

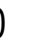
1 +34 9232945 32; fax: +34 923224876

Analysis of the occurrence and distribution of the Omp25/Omp31 family of surface proteins in the six classical Brucella species

Ana I. Martín-Martín ${ }^{a}$, Paola Caro-Hernández ${ }^{\mathrm{a}}$, Pilar Sancho ${ }^{\mathrm{a}}$, Carmen Tejedor $^{\mathrm{a}}$, Axel

Cloeckaert $^{\mathrm{b}}$, Luis Fernández-Lago ${ }^{\text {a }}$, Nieves Vizcaíno ${ }^{\text {a,* }}$

${ }^{\text {a }}$ Departamento de Microbiología y Genética, Edificio Departamental, Universidad de Salamanca, Plaza Doctores de la Reina s/n, 37007 Salamanca, Spain

${ }^{\mathrm{b}}$ INRA, UR1282, Infectiologie Animale et Sante Publique, IASP, Nouzilly F-37380, France

9 * Corresponding author: Departamento de Microbiología y Genética, Edificio Departamental, 0 Universidad de Salamanca, Plaza Doctores de la Reina s/n, 37007 Salamanca, Spain. Tel.: 
1

2

3

4

5

6

7

\section{Abstract}

Members of the Omp25/Omp31 family of surface proteins were previously shown to participate in the virulence of some Brucella species and a different distribution of the seven proteins of this family among species could be related to the difference in pathogenicity and host preference they exhibit. Accordingly, in this work we have analyzed the expression of the genes coding for the Omp25/Omp31 family in the six classical Brucella species and a set of B. ovis mutant strains with each omp gene inactivated. Immunoblot of whole cell lysates with antibodies raised against the purified recombinant outer membrane proteins (OMPs) did not show the simultaneous presence of the seven OMPs in any of the Brucella strains studied, but different Omp25/Omp31 profiles were detected, in our experimental conditions, between the Brucella strains representative of the six classical species. Transcripts for omp 31 , omp 25 and omp25c were, in general, the most abundant of the family and some hits were found in $B$. ovis for a posttranscriptional regulation mechanism and for a compensatory mechanism increasing the synthesis of a protein to compensate for the absence of another one. Finally, the potential interest of Omp25c and Omp31b as subcellular vaccines, considering their occurrence in the Brucella strains studied and their antigenic relatedness with other proteins of the family, is discussed.

Keywords: Brucella; Omp25/Omp31 family; outer membrane protein; vaccine; RNA 

for the seven members of the Omp25/Omp31 family in the six classical Brucella species.

\section{Introduction}

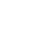

Brucellosis, an infectious disease caused by bacteria of the genus Brucella, can affect many mammal species and is transmissible to humans, thus having an important socioeconomic impact. The six classical Brucella species (B. melitensis, B. abortus, B. suis, B. canis, B. ovis and B. neotomae) (Osterman and Moriyón, 2006) infect terrestrial mammals with a marked host preference and B. ceti, B. pinnipedialis and B. microti have recently been validly published to include Brucella strains preferentially infecting cetaceans, seals and common voles respectively (Foster et al., 2007; Scholz et al., 2008).

The Brucella species show high DNA-DNA relatedness (Verger et al., 1985) but display differences in pathogenicity and host preference which might be related, at least in part, with differences in the composition of the outer membrane $(\mathrm{OM})$, structure involved in the interaction of gram-negative bacteria with the surrounding environment. The Brucella Omp25/Omp31 family is constituted by seven homologous OM proteins (OMPs) (Salhi et al., 2003; Vizcaíno et al., 2004) some of which are involved in virulence (Caro-Hernández et al., 2007; Edmonds et al., 2002; Martín-Martín et al., 2008) and whose encoding genes exhibit DNA polymorphism among the brucellae (Vizcaíno et al., 2004). Omp31 and Omp25 are major OMPs with a well-studied distribution in Brucella (Cloeckaert et al., 2002) but regarding the other members of the family, although they have been detected in at least one Brucella species (Al Dahouk et al., 2008; Cloeckaert et al., 2002; Connolly et al., 2006; Eschenbrenner et al., 2006; Guzmán-Verri et al., 2002; Salhi et al., 2003; Wagner et al., 2002), little is known about their occurrence among the brucellae. 


\section{Materials and methods}

\subsection{Plasmids and bacterial strains}

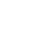

Plasmids (Table 1) were propagated in Escherichia coli JM109 or BL21(DE3) cultured in Luria-Bertani medium supplemented with ampicillin (Amp).

For construction of pNV31b-com (containing omp31b of B. abortus 544 under the control of the lacZ promoter), omp31b was PCR-amplified with primers $31 \mathrm{~b}-\mathrm{F} 2$ and $31 \mathrm{~b}-\mathrm{R} 2$ (Table 2) and cloned into pGEM-T Easy in the same direction to lacZ. The SpeI-SacII insert was finally cloned into SpeI/SacII-digested pBBR1MCS-4 (Kovach et al., 1995).

Brucella strains (Table 1) -propagated in tryptic soy agar supplemented with $0.3 \%$ yeast extract and 5\% horse serum (Caro-Hernández et al., 2007)- were incubated at $37{ }^{\circ} \mathrm{C}$ (44 $\mathrm{h}$ for B. melitensis Rev.1 and B. ovis and $20 \mathrm{~h}$ for the other strains, in order to reach a growth level starting to be clearly visible and similar for all the strains) and a $10 \% \mathrm{CO}_{2}$ atmosphere was used for B. ovis and B. abortus. Culture medium for B. ovis PA-derived strains was supplemented with Amp, kanamycin (Kan) or both depending on their antibiotic resistance pattern (Table 1).

Recombinant plasmid pNV31b-com (see above) was introduced in B. ovis PA by electroporation, as previously reported (Vizcaíno et al., 2004), to obtain B. ovis PNV31b-com. The other genetically-modified B. ovis strains were previously described (Caro-Hernández et al., 2007; Vizcaíno et al., 2004).

\subsection{Primers and nucleic acid techniques}


Primers (Table 2) (Roche, Mannheim, Germany) were chosen according to the

2 published Brucella genome sequences. PCR and DNA sequencing were previously detailed

3 (Caro-Hernández et al., 2007).

RNA was extracted (from $1 \mathrm{ml}$ of an aqueous bacterial suspension concentrated to obtain an O.D.600 nm of 13) following a RNeasy midi kit (Qiagen GmbH, Hilden, Germany) modified protocol (Bellaire et al., 2003) and quantified spectrophotometrically.

RNA (1 $\mu \mathrm{g})$ was treated with RQ1 DNase (Promega) and subjected to cDNA synthesis with the transcriptor first strand cDNA synthesis kit (Roche) using the provided random hexamers as primers for reverse transcriptase (RT). The subsequent PCR reactions were performed using $1 \mu 1$ of cDNA as template and the specific primers for each target omp gene

(Table 2). Products amplified by RT-PCR were visualized after electrophoresis in $0.8 \%$ agarose gels. Absence of DNA contamination in RNA samples was confirmed with identical reactions but omitting the reverse transcriptase (no amplification products were detected with these reactions). A control RT-PCR reaction with the $I F-1$ gene -constitutively expressed in Brucella (Eskra et al., 2001)- was also settled.

\subsection{Production of anti-OMP immune sera}

First, the region corresponding to each mature protein of the Omp25/Omp31 family was PCR-amplified, using the pair of primers described in Table 2, from a Brucella strain bearing a functional gene (Vizcaíno et al., 2004): B. ovis PA (omp25c, omp25d and omp22), B. melitensis 16M (omp25b) or B. abortus 544 (omp31b). The primers -except those used for omp22- were designed to introduce a 5'-terminal BglII or BamHI site and a 3'-terminal SfuI site in the amplified gene. The amplicons were ligated into pGEM-T Easy, cleaved with the 
1 pTrcHisA (Table 1). For omp22 higher levels of the recombinant protein were obtained

2 following another cloning strategy. The gene omp22 of B. ovis PA was amplified with primers 3 22MAT-F and 22R, cloned into pGEM-T Easy in the same orientation to lacZ, then into $4 \quad$ SphI/SalI-digested pUC19 and finally, into BamHI/HindIII-digested pTrcHisA.

The resulting plasmids (Table 1) -showing the expected nucleotide sequence- were introduced by transformation into E. coli JM109 and BL21(DE3) where the expression of each recombinant gene was induced for $6 \mathrm{~h}$ with IPTG (Guilloteau et al., 1999) to evaluate, by SDS-PAGE and Commassie blue staining, the level of synthesis of each recombinant protein. Strain BL21(DE3) provided better results than JM109 except for omp25b.

The recombinant fusion proteins (having a 5 '-histidine tag) were purified (from E. coli cells incubated for $6 \mathrm{~h}$ in the presence of IPTG) with the ProBond Purification System (Invitrogen) under denaturing conditions. The protein fractions -dialyzed against deionised water- were analyzed by Coomassie blue staining following SDS-PAGE and quantified with the Bio-Rad protein assay (Bio-Rad, Hercules, California, USA).

Female New Zealand albino rabbits were inoculated subcutaneously -three times at weekly intervals- with $50 \mu \mathrm{g}$ of sonicated purified protein in Freund's complete (1st immunization) or incomplete (2nd and 3rd immunization) adjuvant. Seven days after the last injection, blood was taken by heart puncture to obtain the serum.

\subsection{Immunological techniques}

Rabbit sera (1/50 dilution) and monoclonal antibodies (MAbs) A59/05F01/C09 (C09) -specific for the Brucella spp. Omp25 protein- and A59/10F09/G10 (G10) and A01/08H06/G02 (G02) -reacting in Western blot with the B. melitensis and B. ovis Omp31 protein, respectively- were used (Cloeckaert et al., 1990; Vizcaíno et al., 2001). SDS-PAGE 
1 and Western blot with whole-cell lysates (bacterial suspensions concentrated to an O.D.600 nm

2 of 20, diluted 1/2 in Laemmli sample buffer and boiled for $10 \mathrm{~min}$ ) or purified recombinant

3 proteins were previously described (Vizcaíno et al., 2001). The low range SDS-PAGE

4 standard (Bio-Rad) was used to determine, as instructed by the manufacturer, the molecular 5 mass of the proteins of the Omp25/Omp31 family. The proteins transferred to the 6 nitrocellulose membrane following SDS-PAGE were stained with Ponceau S (Sigma, St. 7 Louis, MO, USA) to verify the accuracy of transfer and the total protein charge (which was 8 similar for all the whole cell lysates of the different Brucella strains). Goat anti-rabbit and 9 anti-mouse IgG-peroxidase conjugates (Sigma) were used and the blots were never stripped and reprobed. When the nitrocellulose membrane was cut into strips for independent development, their realignment (to reproduce the original nitrocellulose membrane) was performed before analyzing the results.

For adsorption of the anti-Omp22 serum, purified Omp22 was submitted to SDSPAGE and transferred to nitrocellulose. The intense Omp22 band on the membrane was cut, saturated with skim milk and incubated overnight with the serum diluted 1/200 (Vizcaíno et al., 2001). Binding of antibodies to Omp22 was checked as for Western blot. The procedure was repeated until complete removal of the anti-Omp22 antibodies. Unadsorbed control serum was incubated with saturated nitrocellulose under the same conditions. Other anti-OMP sera were similarly adsorbed with the corresponding OMP.

\section{Results}


Transcription of omp25b in B. ovis PA (lacking omp25b (Vizcaíno et al., 2004)) was

2 not detected by RT-PCR while transcripts for the other genes of the family were clearly

3 evidenced (Fig. 1). The B. ovis PA genetically-modified strains (Fig. 1B) gave the expected

4 RT-PCR pattern when compared to the parental strain: (i) absence of transcript for the

5 corresponding inactivated omp gene, with the exception of the unexpected omp 25 faint band

6 in the $\Delta o m p 25$ mutant (although these transcripts should not have a ribosome binding site and

7 the synthesis of Omp25 was not detected in the $\Delta o m p 25$ mutant by reactivity with monoclonal

8 or polyclonal antibodies [Fig. 3 and data not shown]), (ii) over-transcription after in trans

9 complementation of the mutant with the wild-type gene -only tested for strains PNV25dAcom and PNV22A-com (complemented $\Delta o m p 25 d$ and $\Delta o m p 22$ mutants respectively)-, (iii) over-transcription of omp31b in strain PNV31b-com (parental strain complemented with undefective omp31b from $B$. abortus), and (iv) detection of omp25b transcripts in strain PNV998-10 (parental strain complemented with a DNA fragment containing omp25b). (lanes 1) was positive in all the strains except in B. abortus strains (lacking omp31 (Vizcaíno et al., 1999; Vizcaíno et al., 1997)). Transcripts for omp31b (lanes 2) were detected in all the strains, although in B. melitensis strains -having a DNA deletion affecting the 5 ' end of omp31b (García-Yoldi et al., 2005; Vizcaíno et al., 2004)- amplification was exclusively obtained with the pair of primers $31 \mathrm{bRT}-\mathrm{R} / 31 \mathrm{bMRT}-\mathrm{F}$. Transcripts for omp25 and omp $25 \mathrm{~b}$ (lanes 3 and 4) were evidenced in all the Brucella strains tested (except omp25b in B. ovis as described above). An intense DNA band revealed the presence of omp25c transcripts (lanes 5) in all the strains, while the RT-PCR reactions for omp25d and omp22 gave less-intense bands (lanes 6 and 7). 
Occurrence of Omp31 in the genus Brucella has been previously studied (Caro-

Hernández et al., 2007; Vizcaíno et al., 1997) and was included in this study as a reference for detection of Omp31b.

The characteristic multiple band pattern for B. ovis Omp31 (Caro-Hernández et al., 2007; Vizcaíno et al., 2001) in Western blot (with two major bands of 28.8 and $30.2 \mathrm{kDa}$ ) was revealed with the anti-Omp31 MAb G02 in all the B. ovis PA strains (representative profile in Fig. 2, lane 2), except the $\Delta o m p 31$ mutant (not shown, (Caro-Hernández et al., 2007)). The other Brucella strains, except those belonging to the species B. abortus (lacking omp31 (Vizcaíno et al., 1999; Vizcaíno et al., 1997)), reacted with the anti-Omp31 MAb G10 (Fig. 2).

With the anti-Omp31b polyclonal antibodies (Fig. 2), all the B. ovis PA-derived strains, except the $\Delta o m p 31$ mutant (lane 5), revealed the same band pattern developed by the anti-Omp31 MAb (lanes 1-9). Accordingly and since the absence of Omp31b is expected in B. ovis considering DNA data (Vizcaíno et al., 2004), it is inferred that the reactivity of the anti-Omp31b serum with $B$. ovis is due to a cross-serological reaction with Omp31 and not to a specific reaction with Omp31b. Additionally, B. ovis-PNV31b-com (parental strain complemented in trans with undefective omp31b from $B$. abortus) displays an additional multiple band profile with a higher molecular mass (starting at about $31 \mathrm{kDa}$ ) (lane 3), which should correspond to over-synthesized Omp31b.

Regarding the reactivity of the other Brucella species with the anti-Omp31b serum (Fig. 2), B. abortus strains -lacking Omp31 (Vizcaíno et al., 1999; Vizcaíno et al., 1997) and 
1 smeared protein band of about $31 \mathrm{kDa}$ (lanes 20 and 22-26), also detected in B. neotomae and

2 B. suis (lanes 16 and 18), probably corresponding to Omp31b. Cross reactivity of the anti-

3 Omp31b serum with Omp31 was also observed with the two latter strains since this serum

4 also developed the protein band revealed with MAb G10 (lanes 16-19), as it also did with $B$.

5 melitensis and B. canis (lanes 12-15). However, as expected according to the nucleotide 6 sequence of omp31b in B. melitensis and B. canis (Vizcaíno et al., 2004), Omp31b was not 7 detected in these strains.

\subsubsection{Omp25 and Omp25b}

Detection by immunoblotting of Omp25 in the genus Brucella has been previously performed (Caro-Hernández et al., 2007; Cloeckaert et al., 1996) and was included in this study as a reference for the identification of the other homologous proteins. As expected (Caro-Hernández et al., 2007; Cloeckaert et al., 1996), detection of Omp25 with MAb C09 only failed with the $\Delta o m p 25$ mutant of B. ovis PA (Fig. 3A). In B. ovis, two bands corresponding to Omp25 were detected: the major band exhibiting an apparent molecular mass $(25.9 \mathrm{kDa})$ lower than that of Omp25 of the other Brucella species $(27.5 \mathrm{kDa})$ and the minor band (more intense in strain PNV31A) of $22.3 \mathrm{kDa}$.

Omp25b was not detected in $B$. ovis (lacking omp25b due to a DNA deletion (Vizcaíno et al., 2004)) except in strain PNV998-10 (Fig. 3B, lanes 1-4) (complemented in trans with the deleted DNA (Vizcaíno et al., 2004)) where Omp25b appeared as a protein band of $32.1 \mathrm{kDa}$ (Fig. 3B, lane 4) also developed with the anti-Omp25c serum (not shown). Regarding the other species, the Omp25b band -disappearing after adsorption of the antiOmp25b serum with purified recombinant Omp25b (not shown)- was only detected in B. suis and B. melitensis (Fig. 3B, lanes 6-8, and data not shown). A couple of bands located under 
1 Omp25b, revealed with the anti-Omp25b serum in several Brucella strains (Fig. 3B), could

2 not be associated to any member of the Omp25/Omp31 family.

The anti-Omp25b serum (Fig. 3B) cross-reacted with Omp25 and Omp25c, according

4 to its reactivity with parental B. ovis $\mathrm{PA}$ and with the $\Delta o m p 25$ and $\Delta o m p 25 c$ mutant strains

5 (lanes 1-3), the reactivity of the anti-Omp25 MAb C09 (lane 5 and data not shown) and the

6 results obtained with the anti-Omp25c serum (Fig. 4A).

7

3.2.3. Omp25c, Omp25d and Omp22

9

The anti-Omp25c serum (Fig. 4A) developed two intense bands of 27.5 and 29.5-30.5 $\mathrm{kDa}$ in $B$. ovis (except in the $\Delta o m p 25 c$ mutant), the smeared upper band being more intensely marked in strains PNV31A and PNV25cA-com (lanes 1-7). This serum also cross-reacted with the B. ovis Omp25 protein, since it reacted with a protein developed with all the B. ovis strains except with the $\Delta o m p 25$ mutant (lanes 1-7). A smeared protein band of 29.5-30.5 kDa and a protein of $27.5 \mathrm{kDa}$ were also detected in the other Brucella species but since Omp25 has in these species the same apparent molecular mass than the lower Omp25c band (see representative reactivity of $B$. canis with $\mathrm{MAb} \mathrm{C} 09$ in lane 8) it is difficult to elucidate whether the $27.5 \mathrm{kDa}$ band is constituted by Omp25 or by both Omp25 and Omp25c. Two additional bands of lower molecular mass and unknown nature were also revealed in $B$. abortus strains (lanes 14-18).

Contrarily, Omp25d was only detected in B. ovis PNV25dA-com (Fig. 4B and data not shown) -strain where omp25d is over-transcribed in comparison with the parental strain (Fig. 1B)- as a protein of approximately $27.9 \mathrm{kDa}$ whose reactivity with the anti-Omp $25 \mathrm{~d}$ serum disappeared after adsorption of the serum with purified Omp25d (not shown). 
The Omp22 protein band -disappearing after adsorption of the anti-Omp22 serum

2 with recombinant Omp22 (not shown)- was detected in all the B. ovis strains except in the

3 somp22 mutant (Fig. 4C, lanes 1-8). However, Omp22 in the complemented $\Delta$ omp22 mutant

4 (B. ovis PNV22A-com) was only detected, as a very faint band, with a more concentrated

5 specific anti-serum (1/10 dilution). Surprisingly, low levels of Omp22 were evidenced in the

B. ovis PA $\Delta$ omp25d mutant and its corresponding complemented strain (lanes 5-6). A protein

7 band showing a molecular mass similar to Omp22 was observed in B. canis, B. neotomae and

8 in B. abortus strains 544, B19 and 45/20. However, adsorption of the anti-Omp22 serum with

9 purified Omp22 only removed its reactivity with B. neotomae.

\section{Dicussion}

Expression in Brucella spp. of the seven genes coding for the OMPs of the

Omp25/Omp31 family was evaluated in this work by RT-PCR and immunological detection of each protein with specific antibodies. In spite of the fact that direct detection of the proteins has not been performed, this study provides for the first time evidences for the synthesis of

Omp31b in B. neotomae, of Omp25c in B. ovis, B. canis and B. neotomae and of Omp22 in B.

ovis and B. neotomae.

The simultaneous presence of the seven members of the family, which according to DNA data would only be feasible in B. suis and B. neotomae (Vizcaíno et al., 2004), was evidenced in none of the strains analyzed, although the limitation of the immunological detection must be considered. In the experimental conditions used, the smooth or rough phenotype does not seem to influence the OM composition regarding the Omp25/Omp31 family (see similar profiles of $B$. abortus 2308 and its derivative rough mutant B. abortus RB51) but a different distribution of the surface proteins of the Omp25/Omp31 family was 
1 observed between the Brucella species (Fig. 2-4), which could contribute to the divergence in

2 pathogenicity and host preference they exhibit. An apparent increase of Omp25c was

3 observed in the $\Delta o m p 31$ mutant of $B$. ovis PA, when compared to the parental strain and to

4 the other mutants derived from the same strain (Fig. 4A), which could be related to a

5 compensatory mechanism necessary to restore the balance of the OM after removal of major

6 Omp31. A compensatory mechanism has been reported for the orthologous Hbp family of

7 Bartonella quintana and for the Omp25/Omp31 family in B. suis 1330 (Minnick et al., 2003;

8 Salhi et al., 2003), and a tight balance of its members was revealed essential for the stability

9 of the OM in B. ovis PA (Caro-Hernández et al., 2007).

Several results described in this work agree with previous DNA polymorphism observations suggesting the absence of some members of the Omp25/Omp31 family in several species (Vizcaíno et al., 2004) and justify why some proteins were not detected even in cases where specific transcripts were evidenced. Thus, defects in or deletion of the encoding-genes (Cloeckaert et al., 1996; Vizcaíno et al., 2004; Vizcaíno et al., 1999; Vizcaíno et al., 1997) explain the unsuccessful detection of Omp31 in B. abortus, of Omp31b in B. melitensis, B. canis and B. ovis, of Omp25b in B. abortus, B. canis and B. ovis and the lower molecular mass exhibited by Omp25 in B. ovis (Fig. 2-4 and data not shown).

The highly conserved sequence of omp25c in the genus (Vizcaíno et al., 2004) and the abundance of its specific transcripts (Fig. 1) justify the detection of Omp25c in all the strains analyzed (Fig. 4A). Moreover, Omp25c seems to be in B. ovis one of the most abundant of the family in the conditions of our experiments (Fig. 2-4). On the contrary and in agreement with studies failing in the detection of Omp25d in B. melitensis, B. abortus or B. suis by $\mathrm{N}$ terminal microsequencing or mass spectrometry (Connolly et al., 2006; Eschenbrenner et al., 2006; Guzmán-Verri et al., 2002; Lamontagne et al., 2007; Salhi et al., 2003; Wagner et al., 2002), Omp25d was not detected in any of the wild-type Brucella strains. Accordingly, it is 
1 probable that the protein co-migrating with Omp25 in B. suis and suggested to be Omp25d by

2 Salhi et al. (Salhi et al., 2003) does not actually correspond to Omp25d but to the lower

3 molecular mass band of Omp25c -that in B. suis would co-migrate with Omp25 (Fig. 4A).

4 The detection of this Omp25c band was possible in B. ovis (Fig. 4A) because the apparent

5 molecular mass of Omp25 in B. ovis is lower than in the other brucellae (Fig. 3A and 4A)

6 (Cloeckaert et al., 1996). A posttranscriptional control mechanism -related to either the

7 translation or the protein turnover rates- could be on the basis of the lack of detection of

8 Omp25d in Brucella spp., since omp25d is highly conserved in the genus, does not show

9 sequence defects, has a clear ribosome binding site (Vizcaíno et al., 2004), and is transcribed

10 in all the strains analyzed (Fig. 1). Such mechanism could also explain why, in spite of the

11 clear detection of Omp22 in B. ovis PA (Fig. 4C), a marked over-transcription of omp22 in

12 strain PNV22A-com ( $\Delta o m p 22$ mutant complemented with wild-type omp22) (Fig. 1B) leads

13 to almost undetectable levels of Omp22 in our conditions (Fig. 4C).

14 Omp22 was only detected in B. ovis and B. neotomae while in other Brucella strains a

15 protein band of the same molecular mass could not be assigned to Omp22 after adsorption of 16 the anti-Omp22 serum with purified Omp22 (Fig. 4C). However, the presence of Omp22 in $B$.

17 canis RM6/66, B. suis 1330 and B. abortus strains 544, B19 and 45/20 can not be completely

18 excluded since the protein/s of molecular mass similar to Omp22 and reacting with the anti-

19 Omp22 serum would prevent the accurate identification of Omp22. Omp22 was not detected

20 in B. abortus 2308 (Fig. 4C, lane 16), in contrast to previous works evidencing Omp22 in this

21 strain after mass spectrometry studies with OM fragments or cell envelop extracts (Connolly

22 et al., 2006; Guzmán-Verri et al., 2002). These differences might be related, in addition to the

23 detection techniques, to the different culture conditions or the fact that we have used whole

24 cell extracts. 
The attenuation in virulence demonstrated for B. ovis-PNV25dA (Caro-Hernández et

2 al., 2007) and its defects in invasiveness and intracellular multiplication in professional and

3 non-professional phagocytes (Martín-Martín et al., 2008) would support the synthesis of

4 Omp25d in B. ovis PA. However, as described for other homologous genes in other bacteria

5 (Motaleb et al., 2004), this B. ovis $\Delta$ omp25d mutant synthesizes lower amounts of Omp22

6 (Fig. 4C) despite transcription of omp22 seems similar to that of the parental strain (Fig. 1).

7 Since the $\Delta o m p 22$ mutant is avirulent and unable to survive inside phagocytes while these defects are less prominent in the $\Delta o m p 25 d$ mutant (Caro-Hernández et al., 2007; MartínMartín et al., 2008), it seems probable that the alterations in the latter mutant be due -at least in part- to the decrease in Omp22. Normal levels of Omp22 were not recovered after complementation of the $\Delta o m p 25 d$ and $\Delta o m p 22$ mutants with the corresponding wild-type genes (Fig. 4C), which also justify why complementation of both strains did not restore the virulence of the parental strain (Caro-Hernández et al., 2007).

Close antigenic relatedness between Omp31 and Omp31b -justified by their $67 \%$ of sequence identity (Salhi et al., 2003) and responsible for the strong reactivity of the antiOmp31b serum with B. ovis lysates (Fig. 2)- were evidenced. Since Omp31 protects against rough B. ovis and smooth B. melitensis infections (Cassataro et al., 2005; Estein et al., 2003), the potential of Omp31b as subcellular vaccine would merit to be evaluated in protecting not only against infection by Brucella species synthesizing Omp31b but also against Brucella species not having Omp31b but synthesizing the antigenically-related Omp31 protein ((Vizcaíno et al., 2004) and Fig. 1). Similarly, the serological cross-reactivity of Omp25c with Omp25 and Omp25b and the fact that it was detected in all the investigated Brucella strains (Fig. 1 and 4A) are also points encouraging its evaluation as subcellular vaccine. A recent report (Al Dahouk et al., 2008) showing that the concentrations of Omp31, Omp31b, Omp25b and Omp25c in B. suis (ORFs BRA0423, BR1622, BR0971 and BR0119, respectively) 
1 increase inside murine macrophages -when compared to those detected in bacteria growing in

2 culture medium- provides additional data reinforcing this evaluation.

3

This study gives new insights into the characterization of the members of the

4 Omp25/Omp31 family of surface proteins, providing a more detailed map about their

5 distribution in the Brucella species and new information supporting the evaluation of some of

6 them as subcellular vaccines against brucellosis.

7 
2

3

This work was financed by projects SA113A06 (Junta de Castilla y León) and

4 PI050091 (Instituto de Salud Carlos III, Ministerio de Sanidad y Consumo), the latter also 5 supporting AIMM.

6 


\section{References}

Al Dahouk, S., Jubier-Maurin, V., Scholz, H.C., Tomaso, H., Karges, W., Neubauer, H., Köhler, S., 2008. Quantitative analysis of the intramacrophagic Brucella suis proteome reveals metabolic adaptation to late stage of cellular infection. Proteomics 8 , 3862-3870.

Bellaire, B.H., Elzer, P.H., Hagius, S., Walker, J., Baldwin, C.L., Roop, R.M., 2nd, 2003. Genetic organization and iron-responsive regulation of the Brucella abortus 2,3dihydroxybenzoic acid biosynthesis operon, a cluster of genes required for wild-type virulence in pregnant cattle. Infect. Immun. 71, 1794-1803.

Caro-Hernández, P., Fernández-Lago, L., de Miguel, M.J., Martín-Martín, A.I., Cloeckaert, A., Grilló, M.J., Vizcaíno, N., 2007. Role of the Omp25/Omp31 family in outer membrane properties and virulence of Brucella ovis. Infect. Immun. 75, 4050-4061.

Cassataro, J., Estein, S.M., Pasquevich, K.A., Velikovsky, C.A., de la Barrera, S., Bowden, R., Fossati, C.A., Giambartolomei, G.H., 2005. Vaccination with the recombinant Brucella outer membrane protein 31 or a derived 27 -amino-acid synthetic peptide elicits a CD4+ T helper 1 response that protects against Brucella melitensis infection. Infect. Immun. 73, 8079-8088.

Cloeckaert, A., de Wergifosse, P., Dubray, G., Limet, J.N., 1990. Identification of seven surface-exposed Brucella outer membrane proteins by use of monoclonal antibodies: immunogold labeling for electron microscopy and enzyme-linked immunosorbent assay. Infect. Immun. 58, 3980-3987.

Cloeckaert, A., Verger, J.M., Grayon, M., Zygmunt, M.S., Grépinet, O., 1996. Nucleotide sequence and expression of the gene encoding the major 25-kilodalton outer 
membrane protein of Brucella ovis: Evidence for antigenic shift, compared with other Brucella species, due to a deletion in the gene. Infect. Immun. 64, 2047-2055.

Cloeckaert, A., Vizcaíno, N., Paquet, J.Y., Bowden, R.A., Elzer, P.H., 2002. Major outer membrane proteins of Brucella spp.: past, present and future. Vet. Microbiol. 90, 229247.

Connolly, J.P., Comerci, D., Alefantis, T.G., Walz, A., Quan, M., Chafin, R., Grewal, P., Mujer, C.V., Ugalde, R.A., DelVecchio, V.G., 2006. Proteomic analysis of Brucella abortus cell envelope and identification of immunogenic candidate proteins for vaccine development. Proteomics 6, 3767-3780.

Edmonds, M.D., Cloeckaert, A., Elzer, P.H., 2002. Brucella species lacking the major outer membrane protein Omp25 are attenuated in mice and protect against Brucella melitensis and Brucella ovis. Vet. Microbiol. 88, 205-221.

Eschenbrenner, M., Horn, T.A., Wagner, M.A., Mujer, C.V., Miller-Scandle, T.L., DelVecchio, V.G., 2006. Comparative proteome analysis of laboratory grown Brucella abortus 2308 and Brucella melitensis 16M. J. Proteome Res. 5, 1731-1740.

Eskra, L., Canavessi, A., Carey, M., Splitter, G., 2001. Brucella abortus genes identified following constitutive growth and macrophage infection. Infect. Immun. 69, 77367742.

Estein, S.M., Cassataro, J., Vizcaíno, N., Zygmunt, M.S., Cloeckaert, A., Bowden, R.A., 2003. The recombinant Omp31 from Brucella melitensis alone or associated with rough lipopolysaccharide induces protection against Brucella ovis infection in BALB/c mice. Microbes Infect. 5, 85-93.

Foster, G., Osterman, B.S., Godfroid, J., Jacques, I., Cloeckaert, A., 2007. Brucella ceti sp. nov. and Brucella pinnipedialis sp. nov. for Brucella strains with cetaceans and seals as their preferred hosts. Int. J. Syst. Evol. Microbiol. 57, 2688-2693. 
1 García-Yoldi, D., Marín, C.M., López-Goñi, I., 2005. Restriction site polymorphisms in the genes encoding new members of group 3 outer membrane protein family of Brucella spp. FEMS Microbiol. Lett. 245, 79-84.

Guilloteau, L.A., Laroucau, K., Vizcaíno, N., Jacques, I., Dubray, G., 1999. Immunogenicity of recombinant Escherichia coli expressing the omp31 gene of Brucella melitensis in BALB/c mice. Vaccine 17, 353-361.

Guzmán-Verri, C., Manterola, L., Sola-Landa, A., Parra, A., Cloeckaert, A., Garin, J., Gorvel, J.P., Moriyón, I., Moreno, E., López-Goñi, I., 2002. The two-component system BvrR/BvrS essential for Brucella abortus virulence regulates the expression of outer membrane proteins with counterparts in members of the Rhizobiaceae. Proc. Natl. Acad. Sci. USA 99, 12375-12380.

Kovach, M.E., Elzer, P.H., Hill, D.S., Robertson, G.T., Farris, M.A., Roop, R.M., 2nd, Peterson, K.M., 1995. Four new derivatives of the broad-host-range cloning vector pBBR1MCS, carrying different antibiotic-resistance cassettes. Gene 166, 175-176.

Lamontagne, J., Butler, H., Chaves-Olarte, E., Hunter, J., Schirm, M., Paquet, C., Tian, M., Kearney, P., Hamaidi, L., Chelsky, D., Moriyón, I., Moreno, E., Paramithiotis, E., 2007. Extensive cell envelope modulation is associated with virulence in Brucella abortus. J. Proteome Res. 6, 1519-1529.

Martín-Martín, A.I., Caro-Hernández, P., Orduña, A., Vizcaíno, N., Fernández-Lago, L., 2008. Importance of the Omp25/Omp31 family in the internalization and intracellular replication of virulent $B$. ovis in murine macrophages and HeLa cells. Microbes Infect., In Press.

Minnick, M.F., Sappington, K.N., Smitherman, L.S., Andersson, S.G., Karlberg, O., Carroll, J.A., 2003. Five-member gene family of Bartonella quintana. Infect. Immun. 71, 814821. 
1 Motaleb, M.A., Sal, M.S., Charon, N.W., 2004. The decrease in FlaA observed in a flaB mutant of Borrelia burgdorferi occurs posttranscriptionally. J. Bacteriol. 186, 37033711.

Osterman, B., Moriyón, I., 2006. International Committee on Systematics of Prokaryotes; Subcommittee on the taxonomy of Brucella: Minutes of the meeting, 17 September 2003, Pamplona, Spain. Int. J. Syst. Evol. Microbiol. 56, 1173-1175.

Salhi, I., Boigegrain, R.A., Machold, J., Weise, C., Cloeckaert, A., Rouot, B., 2003. Characterization of new members of the group 3 outer membrane protein family of Brucella spp. Infect. Immun. 71, 4326-4332.

Scholz, H.C., Hubalek, Z., Sedlácek, I., Vergnaud, G., Tomaso, H., Al Dahouk, S., Melzer, F., Kämpfer, P., Neubauer, H., Cloeckaert, A., Maquart, M., Zygmunt, M.S., Whatmore, A.M., Falsen, E., Bahn, P., Göllner, C., Pfeffer, M., Huber, B., Busse, H.-J., Nöckler, K., 2008. Brucella microti sp. nov., isolated from the common vole Microtus arvalis. Int. J. Syst. Evol. Microbiol. 58, 375-382.

Verger, J.M., Grimont, F., Grimont, P.A., Grayon, M., 1985. Brucella, a monospecific genus as shown by deoxyribonucleic-acid hybridization. Int. J. Syst. Bacteriol. 35, 292-295.

Vizcaíno, N., Caro-Hernández, P., Cloeckaert, A., Fernández-Lago, L., 2004. DNA polymorphism in the omp25/omp31 family of Brucella spp.: identification of a 1.7-kb inversion in Brucella cetaceae and of a 15.1-kb genomic island, absent from Brucella ovis, related to the synthesis of smooth lipopolysaccharide. Microbes Infect. 6, 821834.

Vizcaíno, N., Cloeckaert, A., Zygmunt, M.S., Fernández-Lago, L., 1999. Molecular characterization of a Brucella species large DNA fragment deleted in Brucella abortus strains: evidence for a locus involved in the synthesis of a polysaccharide. Infect. Immun. 67, 2700-2712. 
1 Vizcaíno, N., Kittelberger, R., Cloeckaert, A., Marín, C.M., Fernández-Lago, L., 2001. Minor

2

3

4

5

6

7

8

9

10

11

12

13

14 nucleotide substitutions in the omp31 gene of Brucella ovis result in antigenic differences in the major outer membrane protein that it encodes compared to those of the other Brucella species. Infect. Immun. 69, 7020-7028.

Vizcaíno, N., Verger, J.M., Grayon, M., Zygmunt, M.S., Cloeckaert, A., 1997. DNA polymorphism at the omp-31 locus of Brucella spp.: evidence for a large deletion in Brucella abortus, and other species-specific markers. Microbiology 143, 2913-2921.

Wagner, M.A., Eschenbrenner, M., Horn, T.A., Kraycer, J.A., Mujer, C.V., Hagius, S., Elzer, P., DelVecchio, V.G., 2002. Global analysis of the Brucella melitensis proteome: Identification of proteins expressed in laboratory-grown culture. Proteomics 2, 10471060. 


\section{$1 \quad$ Legends of figures}

2

3 Fig. 1. RT-PCR for omp31 (lanes 1), omp31b (lanes 2), omp25 (lanes 3), omp25b (lanes 4), 4 omp25c (lanes 5), omp25d (lanes 6) and omp22 (lanes 7) in different Brucella species (A) and 5 in the B. ovis mutants with these genes impaired (B). RT-PCR of omp31b in lanes 2 was 6 performed with primers $31 \mathrm{bRT}-\mathrm{F}$ and $31 \mathrm{bRT}-\mathrm{R}$ except in B. melitensis strains $\left(^{*}\right)$ where 7 transcripts were only detected with the pair of primers $31 \mathrm{bMRT}-\mathrm{F} / 31 \mathrm{bRT}-\mathrm{R}$. St, DNA molecular size marker VI (Roche). Control reactions with constitutively expressed $I F-1$ (Eskra et al., 2001) are shown in panel C, where lane numbers correspond to strain numbers in panels A and B. Control RT-PCR reactions without RT gave no amplification product.

Fig. 2. Western blot with whole-cell extracts of different Brucella strains and anti-Omp31 MAbs or polyclonal antibodies obtained against recombinant Omp31b (31b). MAb G02 was used for B. ovis strains while MAb G10 was used for the other Brucella species. Positions of

Omp31 and Omp31b are marked with arrows and strains where Omp31b seems to be detected are identified with an asterisk. The anti-Omp31b serum was used at dilution 1/500 with $B$. ovis PNV31b-com (lane 3) instead of dilution 1/50 as employed for the other strains. A line on the left shows the position of the closest protein of the molecular mass standard.

Fig. 3. Western blot with whole-cell extracts of different Brucella strains and anti-Omp25 MAb C09 (A) or polyclonal antibodies obtained against recombinant Omp25b (B). Strains not represented in panel B did not reveal the Omp25b band with the anti-Omp25b antiserum. Positions of Omp25, Omp25b (confirmed by adsorption of the serum with purified Omp25b as described in section 2.4) and Omp25c are marked with arrows in panel B. Symbols: \#, lane 
1 developed with the anti-Omp25 MAb C09; ?, doubtful or non-identified protein bands. A line

2 on the left shows the position of the closest protein of the molecular mass standard.

3

4 Fig. 4. Western blot with whole-cell extracts of different Brucella strains and polyclonal 5 antibodies obtained against recombinant Omp25c (A), Omp25d (B) or Omp22 (C). Strains not 6 represented in panel B did not react with the anti-Omp25d antiserum. Positions of the proteins 7 of the Omp25/Omp31 family are marked with arrows. Symbols: \#, lane developed with anti8 Omp25 MAb C09; ?, doubtful or non-identified protein bands; *, strains where the presence 9 of Omp22 was confirmed. The anti-Omp22 serum was used at dilution 1/10 with B. ovis PNV22A-com instead of dilution $1 / 50$ as employed for the other strains (the $1 / 10$ dilution 11 gave with the parental strain and the $\Delta o m p 22$ mutant the same results shown in panel C, lanes 121 and 7, respectively). A line shows in each panel the position of the closest protein of the molecular mass standard. 
1 Table 1. Brucella strains and plasmids used in this work

2

\begin{tabular}{|c|c|c|}
\hline Brucella strain or plasmid & Origin $^{a}$ & Relevant characteristics \\
\hline \multicolumn{3}{|l|}{ Brucella strains } \\
\hline \multicolumn{3}{|l|}{ B. melitensis } \\
\hline Rev 1 & BCCN V4a & Smooth vaccine \\
\hline B115 & BCCN R19 & Smooth strain \\
\hline \multicolumn{3}{|l|}{ B. abortus } \\
\hline $544^{\mathrm{b}}$ & BCCN R4 & Smooth strain \\
\hline 2308 & BCCN R10 & Smooth strain \\
\hline B19 & BCCN V1 & Smooth vaccine \\
\hline RB51 & BCCN V5 & Rough vaccine \\
\hline $45 / 20$ & BCCN V2 & Rough strain \\
\hline B. suis $1330^{\mathrm{b}}$ & BCCN R12 & Smooth strain \\
\hline B. canis $\mathrm{RM} 6 / 66^{\mathrm{b}}$ & BCCN R18 & Rough strain \\
\hline B. neotomae $5 \mathrm{~K} 33^{\mathrm{b}}$ & BCCN R16 & Smooth strain \\
\hline \multicolumn{3}{|l|}{ B. ovis } \\
\hline PA (parental) & BCCN 76-250 & Virulent parental rough strain for mutants listed below \\
\hline PNV31A & (Caro-Hernández et al., 2007) & omp31 inactivated. $\operatorname{Kan}^{\mathrm{r}}$ \\
\hline PNV31A-com & (Caro-Hernández et al., 2007) & complemented PNV31 $\mathrm{A}^{\mathrm{c}}$ \\
\hline PNV25A & (Caro-Hernández et al., 2007) & omp25 inactivated. Kan ${ }^{\mathrm{r}}$ \\
\hline PNV25A-com & (Caro-Hernández et al., 2007) & complemented PNV25A ${ }^{c}$ \\
\hline $\mathrm{PNV} 25 \mathrm{cA}$ & (Caro-Hernández et al., 2007) & omp $25 c$ inactivated. $\mathrm{Kan}^{\mathrm{r}}$ \\
\hline PNV25cA-com & (Caro-Hernández et al., 2007) & complemented PNV25cA ${ }^{\mathrm{c}}$ \\
\hline PNV25dA & (Caro-Hernández et al., 2007) & omp25d inactivated. $\operatorname{Kan}^{\mathrm{r}}$ \\
\hline PNV25dA-com & (Caro-Hernández et al., 2007) & complemented PNV25dA ${ }^{\mathrm{c}}$ \\
\hline PNV22A & (Caro-Hernández et al., 2007) & omp22 inactivated. $\mathrm{Kan}^{\mathrm{r}}$ \\
\hline PNV22A-com & (Caro-Hernández et al., 2007) & complemented PNV22A ${ }^{\mathrm{c}}$ \\
\hline PNV31b-com & This work & PA complemented with omp $31 b$ from B. abortus. Amp ${ }^{r}$ \\
\hline PNV998-10 & (Vizcaíno et al., 2004) & $\begin{array}{l}\text { PA complemented with pNV998-10 (plasmid with } \\
\text { omp } 25 b \text { in a } 15 \mathrm{~kb} \text { DNA fragment of } B \text {. melitensis } 16 \mathrm{M} \\
\text { absent in B. ovis). Kan }\end{array}$ \\
\hline \multicolumn{3}{|l|}{ Plasmids } \\
\hline pGEM-T Easy & Promega & PCR-cloning vector. Amp ${ }^{r}$ \\
\hline pUC19 & Fermentas & Cloning vector. Amp ${ }^{\mathrm{r}}$ \\
\hline pBBR1MCS-4 & (Kovach et al., 1995) & Cloning vector replicating in Brucella. Amp ${ }^{\mathrm{r}}$ \\
\hline $\mathrm{pTrcHis} \mathrm{A}$ and $\mathrm{B}$ & Invitrogen & Cloning vectors for protein synthesis and purification. \\
\hline pNV31b-com & This work & omp $31 b$ of $B$. abortus 544 cloned in pBBR1MCS- 4 \\
\hline pNV31b304 & This work & Mature ${ }^{\mathrm{d}}$ omp $31 b$ in $\mathrm{pTrcHis} \mathrm{B}$ \\
\hline pNV25b305 & This work & Mature ${ }^{\mathrm{d}}$ omp $25 b$ in $\mathrm{pTrcHis} \mathrm{A}$ \\
\hline pNV25c306 & This work & Mature ${ }^{\mathrm{d}}$ omp $25 \mathrm{c}$ in $\mathrm{pTrcHis} \mathrm{A}$ \\
\hline pNV25d303 & This work & Mature ${ }^{\mathrm{d}}$ omp $25 d$ in $\mathrm{pTrcHis} \mathrm{A}$ \\
\hline pNV22303 & This work & Mature ${ }^{\mathrm{d}}$ omp 22 in $\mathrm{pTrcHis} \mathrm{A}$ \\
\hline \multicolumn{3}{|c|}{ a BCCN, Brucella Culture Collection, Nouzilly, France } \\
\hline \multicolumn{3}{|l|}{${ }^{b}$ Reference strains } \\
\hline \multicolumn{3}{|c|}{ c Mutant strains complemented with the corresponding wild-type omp gene cloned into pBBR1MCS-4 (Kan and Amp resistant) } \\
\hline \multicolumn{3}{|c|}{${ }^{d}$ Gene region corresponding to the mature OMP without the signal peptide } \\
\hline
\end{tabular}


1

2

Table 2. DNA primers used in this work

\begin{tabular}{lll}
\hline Primer name $^{\prime}$ & \multicolumn{1}{c}{ Nucleotide sequence $^{\mathrm{a}}$} & Target gene (size in bp) $^{\mathrm{b}}$ \\
\hline Construction of pNV31b-com & \\
31b-F2 & GTG ACA GAC ATT GGA GCC & omp31b (1036) \\
31b-R2 & CTC CAG CAA GCC ATT CGC & omp31b
\end{tabular}

Construction of plasmids for the purification of the recombinant Brucella spp. OMPs

31bMAT-BglII
31bR2-SfuI
25bcMAT-BamHI
25bR-SfuI
25cR-SfuI
25dMAT-BamHI
25dR-SfuI
22MAT-F
22R

RT-PCR

31RT-F

31RT-R

31bRT-F

31bMRT-F

31bRT-R

25RT-F

25RT-R

25bRT-F

25bRT-R

$25 \mathrm{cRT}-\mathrm{F}$

25cRT-R2

$25 \mathrm{dRT}-\mathrm{F}$

25dRT-R2

22RT-F

22RT-R

IF1-F

IF1-R
AGA TCT GCC GAC ATC ATC GTT GCT TTC GAA CTC CAG CAA GCC ATT CGC GGA TCC GCT GAC GCC GTC ATT GAA TTC GAA CGC CAT CGC ATT CCG TTG TTC GAA TAT TGG GTG AGG ATT GAC GGA TCC GCG GAT GCC ATT GTT GCG TTC GAA CTG AAG GGT AAA TGC GGC GCC GAC ATG ATG GGA AGG GTT TGA ATC CCG GCT GTT

\section{GAC GTG GTT GTT TCT GA}

GTG TAG AGG TAT TCC GA

TCC GTC GCA ATG TTG TT

GTT CAG GCC GGT TAT AA

GTC GGT GTA GAG GTA TT

GTC TCT CGT AAT CGT CT

ATG TTG TCC GTC AGC TT

TCG CTT CTT CTT GCA TC

AAT CGG ATG TCG TGT GT

TTC TTT TTG CAT CGA CCG

TCG TCG AAG CCG TAA TCC

AAT CTA CTT GGC GCT TC

TGC CGT AAT CGG TGT AGC

TCA AGC GTT CTA TCA CC

TGT TAC GCT GTT CGA TG

ATG GCG AAA GAA GAA GTC CT

TGA AGC GGT AGG TGA TGC GG omp31b (925)

oтp $31 b$

omp25b (742) and omp25c (703)

omp $25 b$

omp $25 \mathrm{c}$

omp25d (749)

omp $25 d$

omp22 (710)

omp 22

omp31 (563)

omp31

omp31b (633)

omp31b (408)

omp $31 b$

omp25 (504)

omp 25

omp 25 (677)

omp $25 b$

omp25c (607)

omp 25 c

omp25d (595)

omp $25 d$

omp22 (588)

omp 22

IF-I (214)

IF-1

4 a Restriction enzymes specific sites in DNA primers are underlined

$5 \mathrm{~b}$ Identification numbers of the genes in the B. suis 1330 published genome sequence (GenBank accession numbers AE014291

6 and AE014292 for chromosome I and II, respectively) are: BRA0423 (omp31), BR1622 (omp31b), BR0701 (omp25),

7 BR0971 (omp25b), BR0119 (omp25c), BR0118 (omp25d), BR1284 (omp22) and BR0249 (IF-1). The size of the PCR-

8 amplified fragments (according to the B. suis 1330 genome sequence) is given in the corresponding forward primer line. 


\section{A} 1. B. owis PA 2. B.melitensis B115 3. B.melitensis Rev1

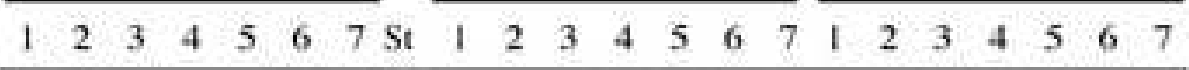

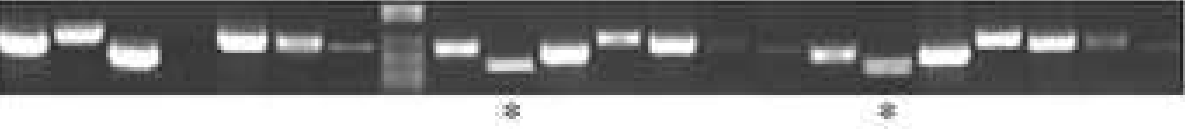

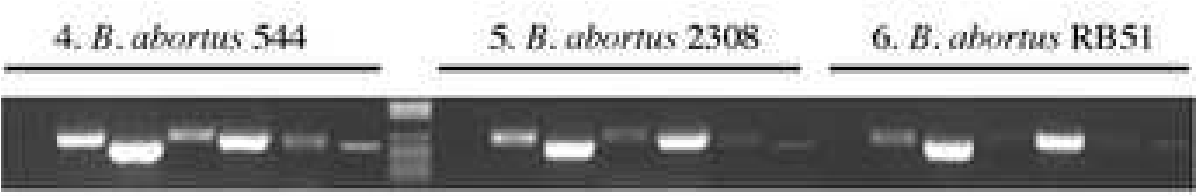

$\frac{\text { 7. B. abortus } 45 / 20}{8.0 . \text { B.abortus B19 }}$

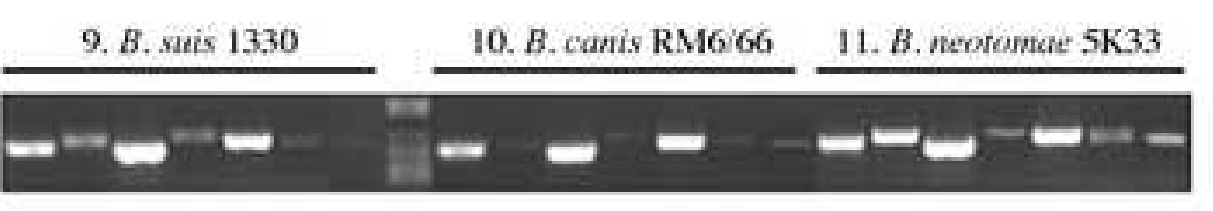

\section{B}

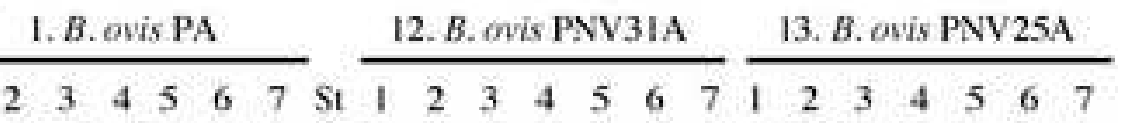

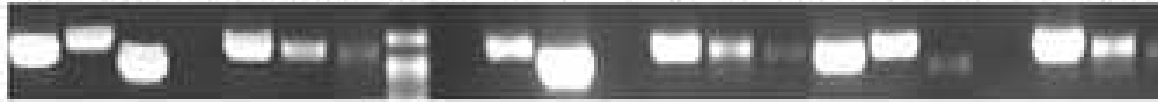

\begin{tabular}{|c|c|c|}
\hline 14. $B$, ovis PNV25eA & 19, B. wis PNV3।b-com & 20. B. owis PNYGgk-10 \\
\hline
\end{tabular}

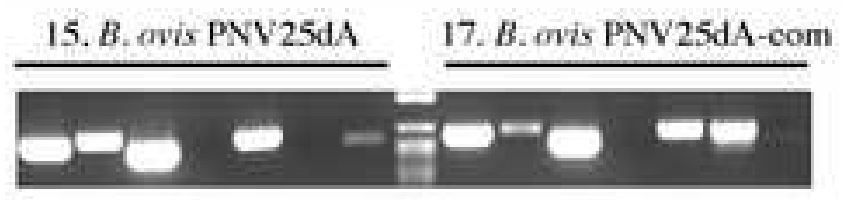

16. B.ovis PNV22A 18. B. wis PNV22A-com

\section{C}

\begin{tabular}{llllllllllllllllllll}
1 & 2 & 3 & 4 & 5 & 6 & 7 & 8 & 9 & 10 & 11 & 12 & 13 & 14 & 15 & 16 & 17 & 18 & 19 & 20 \\
\hline
\end{tabular}




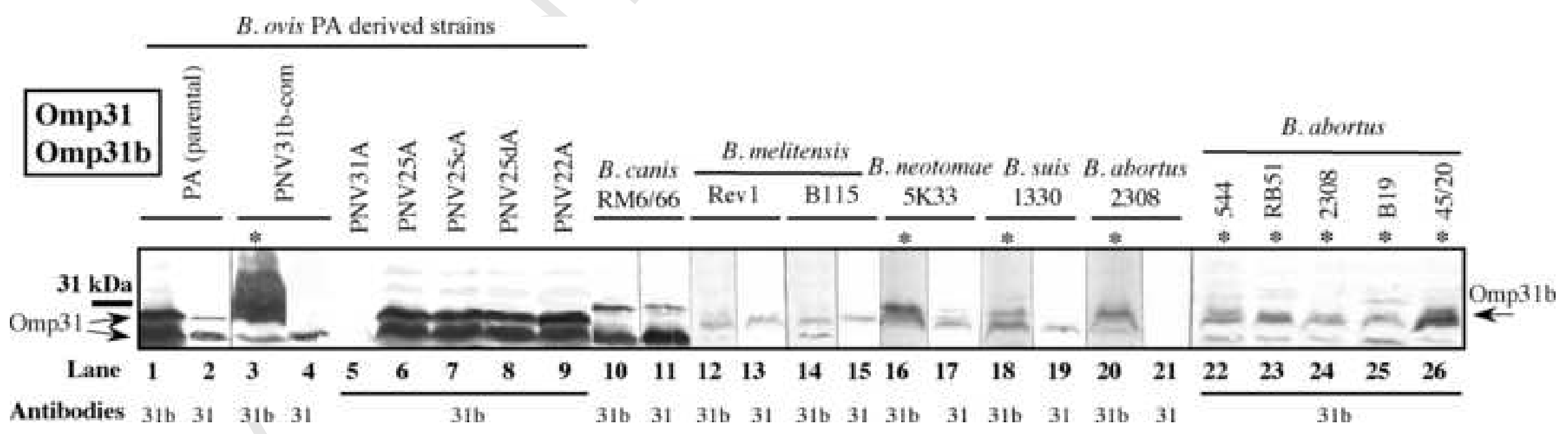




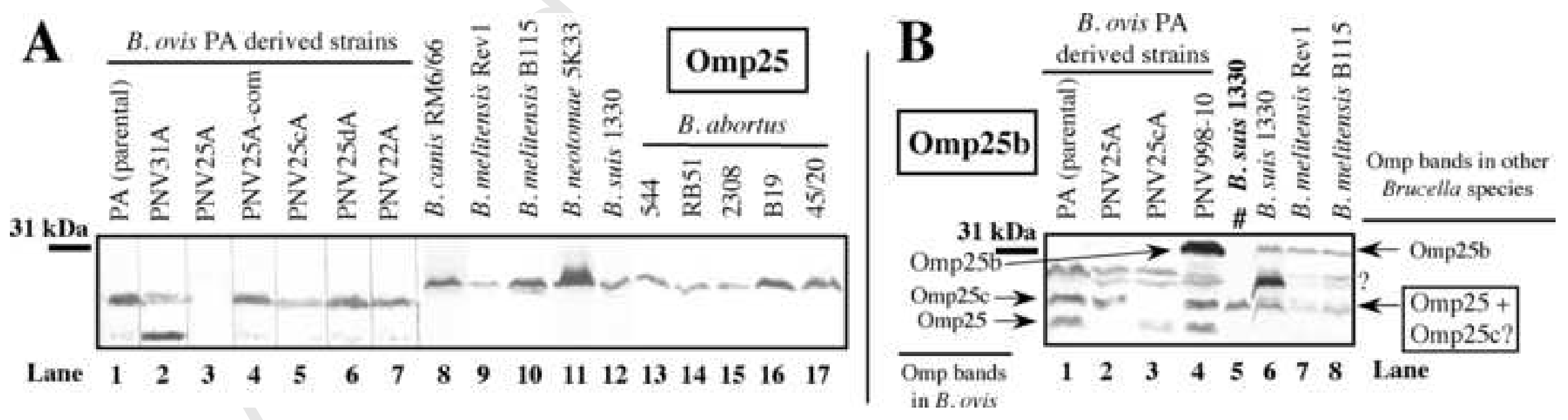



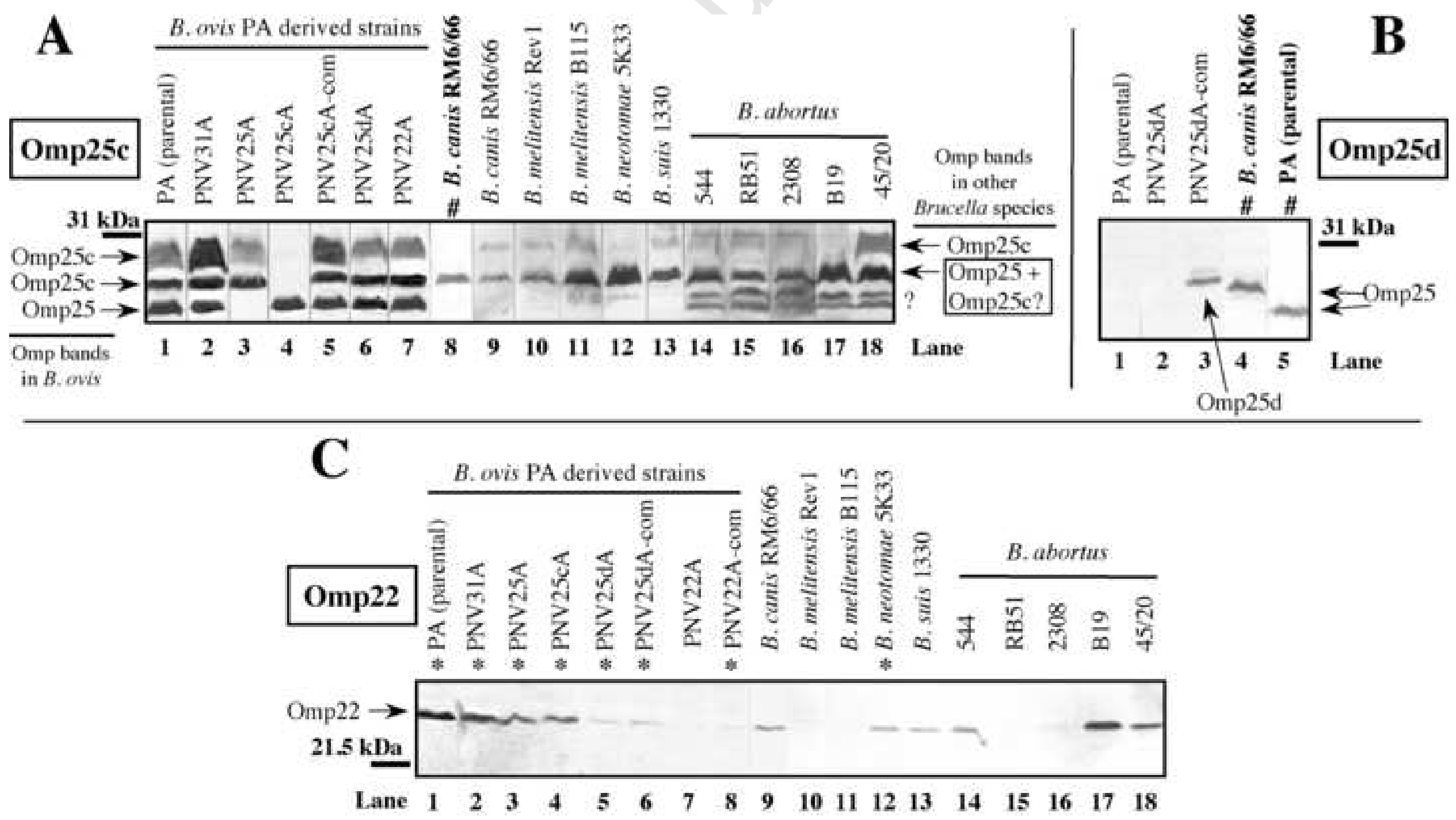